\section{REGIONAL ANESTHESIA IN DIFFICULT AIRWAY: IS IT FOOLISH NOT TO FACE IT?}

${ }^{1} \mathrm{~F}$ Costa, ${ }^{1} \mathrm{LM}$ Remore*, 'A Strumia, ${ }^{1} \mathrm{G}$ Pascarella, ${ }^{1} \mathrm{~S}$ Rizzo, ${ }^{1} \mathrm{~F}$ Gargano, 'V Antinolfi, ${ }^{1} \mathrm{G}$ Frattolillo, ${ }^{1} \mathrm{C}$ Piliego, ${ }^{1} \mathrm{~V}$ Scaduto, ${ }^{2} \mathrm{R}$ Del Buono, ${ }^{1} \mathrm{FE}$ Agrò. ${ }^{1}$ Università Campus Biomedico di Roma, Rome, Italy; ${ }^{2}$ ASST Gaetano Pini, Milan, Italy

\subsection{6/rapm-2021-ESRA.175}

Background and Aims Difficult airway may represent a challenge in anesthesiologists' clinical practice. In some cases regional anesthesia might be an option. Given a preformulated strategy for intubation, the right decision mainly depends on how confident the anesthesiologist is with the appropriate regional technique $[1,2]$.

We describe the case of an impossible to intubate patient, underwent surgical debridement of a neck ulcer under regional anesthesia.

Methods Male 57 y.o. History of nasopharyngeal carcinoma, treated with radiotherapy.

Post-actinic osteonecrosis of the jaw; scar tissue around muscles and vessels of the left side of the neck with consequent lock-jaw and cervical rigidity.

Post-actinic infected lesion of the skin in the lateral, posterior and deltoid regions of the left side of the neck, scheduled for surgical debridement and vac-therapy.

Awake tracheostomy was established as anesthetic management. The patient refused and asked for alternatives.Regional anesthesia was considered. Superficial or intermediate cervical plexus block were not feasible because of the scar tissue. Thus, to cover the area of debridement, a combination of a left ESP block at T2 level and a left deep cervical plexus block at $\mathrm{C} 4$ were performed.

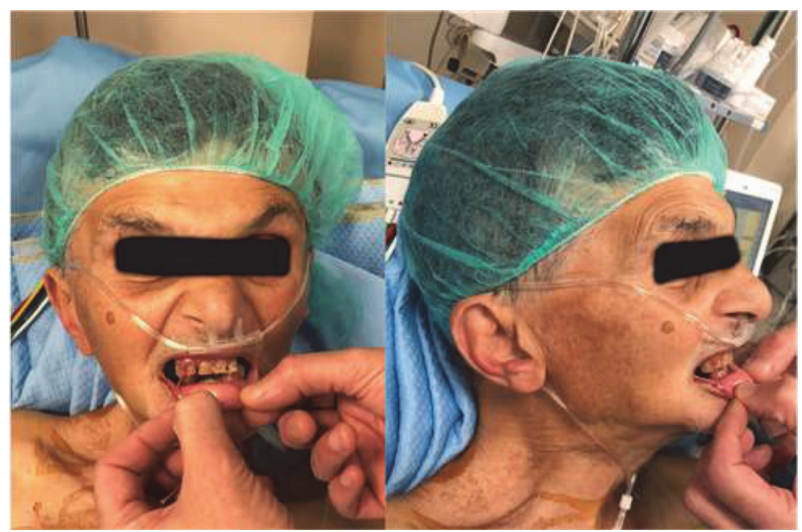

Abstract 175 Figure 1
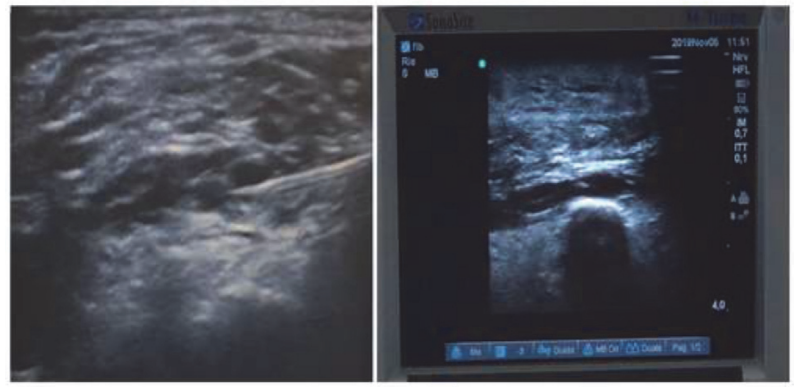

Abstract 175 Figure 2

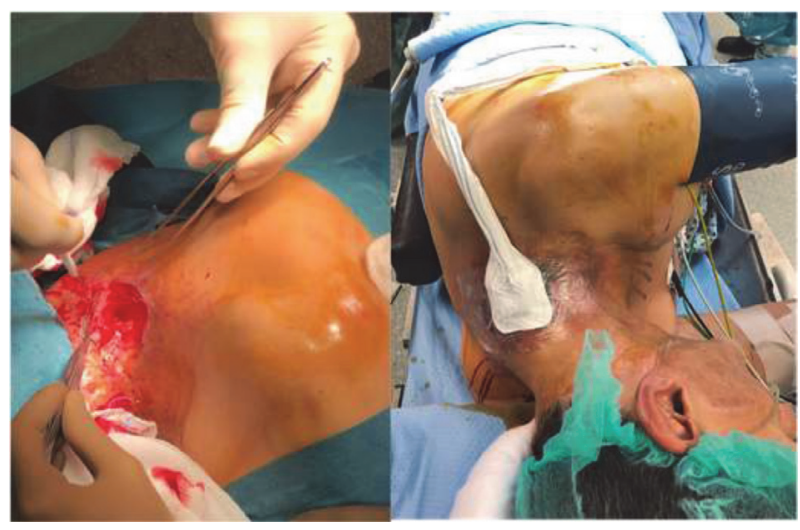

Abstract 175 Figure 3

Awake, trans nasal fiberoptic intubation, was considered as preformulated strategy in case of emergency [3].

Results The surgical procedure was carried out uneventfully with the patient awake and cooperative.

Conclusions Performing regional anesthesia in the difficult airways patients implies major knowledge of the relevant anatomy and techniques. Major skills in airways management are also required. Given these two conditions, it is not always foolish not to secure the airway.

\section{IT IS BETWEEN HEAVEN AND HELL - PATIENTS EXPERIENCES OF PREOPERATIVE PAIN AND PAIN MANAGEMENT AMONG PATIENTS WITH HIP FRACTURE RECEIVING A FEMORAL NERVE BLOCK}

${ }^{1} \mathrm{~A}$ Unneby* ${ }^{2}{ }^{2}$ Gustafson, ${ }^{3} \mathrm{~B}$ Olofsson, ${ }^{3} \mathrm{~B}-\mathrm{M}$ Lindgren. ${ }^{1}$ Umea University, Department of Nursing and Department of Surgical and Perioperative Science Orthopedics, Umeå, Sweden; ${ }^{2}$ Umeå University, Department of Community Medicine and Rehabilitation, Geriatric Medicine, Umeå, Sweden; ${ }^{3}$ Umea University, Department of Nursing, Umeå, Sweden

\subsection{6/rapm-2021-ESRA.176}

Background and Aims Preoperative pain is common and often severe among patients suffering hip fracture. Opioids are usually used but have many side effects. One alternative is a femoral nerve block (FNB). It has been shown to reduce pain and lower the needs for opioids. However, to our knowledge no study has explored qualitatively how patients with hip fracture experiences the treatment with FNB. The aim of this study was to explore experiences of preoperative pain and pain management among patients with hip fracture who had received femoral nerve block.

Methods A qualitative design with semi-structured interviews $(n=23)$ were conducted 2-6 days after surgery. Inclusion criteria were 70 years or older Swedish speaking patients with hip fracture admitted to the the Orthopedic Ward, treated with femoral nerve block before nursing actions. Data was analyzed with qualitative content analysis. This study was approved by a regional ethical review board, Sweden, (DNR 2016/387$31 \mathrm{M})$

Results Our result revealed one theme; hovering between and bell with five sub-themes; experiencing memory loss due to remember the pain and pain management and how the pain were described to be no pain, to worst pain and everything in between; they were dealing with pain in an own way; felt dependent to staff's willingness to relive pain; and that pain management could be lifesaving and a near death experience. 
Conclusions The experience of pain and pain management are between heaven and hell. However, a person-centered pain management are important independent on which pain relief given to achieve well managed pain.

\section{PROLONGED MOTOR BLOCK WITH PERSISTENT SAPHENOUS NEUROPATHY FOLLOWING COMBINED POPLITEAL/SAPHENOUS NERVE BLOCK FOR ANKLE SURGERY}

M Dobrić, B Vinceljek* , J Vukelić Slavić, T Beker. Clinical Hospital Center Sestre Milosrdnice, Traumatology Clinic, Zagreb, Croatia

\subsection{6/rapm-2021-ESRA.177}

Background and Aims Ultrasound guided peripheral nerve block for ankle surgery is appropriate alternative for spinal anaesthesia, allowing for earlier mobilization and adequate postoperative pain control.

Methods 38-year-old female, BMI 20.7, presented for hardware removal a year after an open reduction and internal fixation of bimalleolar ankle fracture. Ultrasound guided popliteal/saphenous nerve block was performed with spinal needle (G25, Quincke), using $0.5 \%$ levobupivacain and dexamethason as an adjuvant to local anaesthetic. Due to poor visualisation of saphenous nerve, paraesthesia was briefly elicited once during the procedure. Surgical procedure

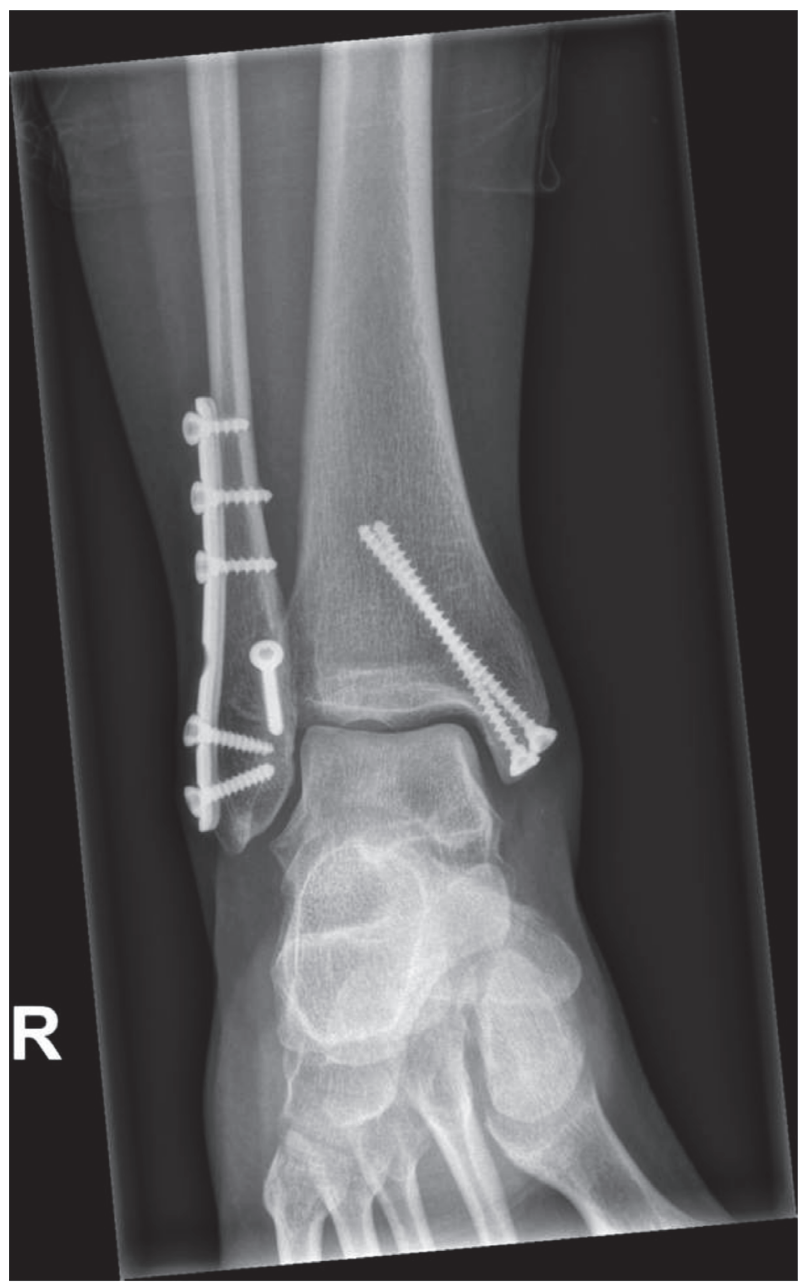

Abstract 177 Figure 1 went uneventfully, in complete surgical block and intravenous sedation with propofol. Motor block persisted for 48 hours, with full recovery thereafter. Sensory deficit in the distribution area of saphenous nerve was present one month after the procedure.

Results The patient was highly satisfied with postoperative pain control with no need for additional analgesics, but concerned about peristing tingling sensation. She declined proposed multimodal treatment for neuropathic pain with calcium channel antagonist pregabalin, and agreed to therapy with NSAID and vitamin B supplements. Further evaluation of eventual prolonged neuropathy, including NMR and nerve conduction studies, was discussed with patient.

Conclusions Dexamethasone prolongs the effect of local anaesthetic when used as an adjuvant. In our case, the duration of motor and sensory block was longer than expected. Complications related to peripheral nerve blocks may go undiagnosed until the first postoperative control. Neural lesions related to peripheral nerve blocks usually resolve within $4-7$ weeks and over $99 \%$ by one year.

\section{WALANT TECHNIQUE IMPROVES THE EFFICIENCY OF DISTAL NERVE BLOCKS FOR CARPAL TUNNEL RELEASE}

${ }^{1} \mathrm{M}$ Doirado*, ${ }^{2} \mathrm{~F}$ Le Sache, ${ }^{2} \mathrm{~L}$ Thomsen, ${ }^{3} \mathrm{G}$ Aziz, ${ }^{3} \mathrm{C}$ Naudin, ${ }^{3} \mathrm{M}$ Merzoug, ${ }^{2} \mathrm{D}$ Barouk, ${ }^{2} \mathrm{M}$ Bucciero, ${ }^{1} \mathrm{~A}$ James, ${ }^{1} \mathrm{C}$ Quemeneur, ${ }^{2} \mathrm{~S}$ Bloc. ${ }^{1}$ Hôpital de la Pitié Salpêtrière, Paris, France; ${ }^{2}$ Clinique Drouot Sport, Paris, France; ${ }^{3}$ CMC Ambroise Paré, Neuilly Sur Seine, France

\subsection{6/rapm-2021-ESRA. 178}

Background and Aims Axillary block is the standard for carpal tunnel release (CTR), providing good anesthesia and tolerance of tourniquet. Distal blocks, efficient and preventing motor block, are less used due to a poor tolerance of tourniquet (1). This study was designed to assess the benefits of the addition of a tumescent local anesthesia (WALANT: Wide Awake Local Anesthesia No Tourniquet) to distal blocks during CTR.

Methods After approval of the Ethics Committee and written informed consent, 30 patients scheduled for CTR were enrolled in this prospective, randomized, open-label study.

Distal blocks (median - ulnar - lateral cutaneous nerve of forearm) were performed under ultrasound with Ropivacaine $0.375 \% \quad(5-7 \mathrm{ml})$ (TOURNIQUET and WALANT groups). In WALANT, an additional infiltration of $7 \mathrm{ml}$ lidocaine and epinephrine was performed in the area of

Abstract 178 Table 1 Patient characteristics

\begin{tabular}{|c|c|c|}
\hline & COETROL (n=15) & WaLART (hois) \\
\hline \multicolumn{3}{|l|}{ Demographica } \\
\hline Mavo, o (\$) & $8(53 \%)$ & $6(405)$ \\
\hline Femalo, $n(S)$ & $7(978)$ & $\theta(80 \mathrm{n})$ \\
\hline Aon, $y$ & $50.5=14.5$ & $55.6 \times 132$ \\
\hline BMS igghe & $28.4=4.5$ & $27.2 \pm 6$ \\
\hline \multicolumn{3}{|l|}{ Medical history } \\
\hline ASA seom & $2(1-3)$ & $2|1-2|$ \\
\hline Dubetes, o (s) & $2(135)$ & $10 \% 3$ \\
\hline Perphersi neuropesty, n (\$) & $0(0 \%)$ & $108 \%$ \\
\hline Altercopathy, n (is) & $3(200)$ & $\theta(7 \times)$ \\
\hline
\end{tabular}

